\title{
Summation and configuration in patterning schedules with the rat and rabbit
}

\author{
WILLIAM P. BELLINGHAM and KATY GILLETTE-BELLINGHAM \\ Australian National University, Canberra, A.C.T., Australia
}

and

E. JAMES KEHOE

University of New South Wales, Kensington, N.S.W., Australia

\begin{abstract}
Discrimination between a tone + light compound and its components in positive and negative patterning schedules was examined. In the positive schedule, reinforced compound presentations $(\mathrm{C}+$ ) were intermixed with unreinforced component presentations $(\mathrm{T}-, \mathrm{L}-$ ). In the negative schedule, the compound was unreinforced $(\mathrm{C}-$ ) and the components were reinforced $(\mathrm{T}+, \mathrm{L}+)$. In $\mathrm{Ex}$ periment 1, appetitive conditioning of rats' anticipatory magazine responses was used, and in Experiment 2, aversive conditioning of the rabbit's nictitating membrane response was used. Both experiments revealed that the positive patterning schedule consistently produced rapid acquisition of appropriate discriminative responding. The results of the negative patterning schedule were more complex. Specifically, the results of Experiment 1 demonstrated that naive rats initially showed rapid acquisition of the negative patterning discrimination. However, schedule reversals revealed that experience with the positive patterning schedule virtually abolished subsequent acquisition of discriminative responding under the negative patterning schedule. The results of Experiment 2 revealed that naive rabbits showed very slow acquisition of discriminative responding under the negative patterning schedule. The results are discussed in relation to the unique-stimulus hypothesis, a contextual encoding hypothesis, and a configural hypothesis.
\end{abstract}

The present experiments examined response acquisition to a compound stimulus and its components as a function of positive and negative patterning schedules. In the positive patterning schedule, reinforced presentations of a compound of tone and light were mixed with unreinforced presentations of the separate components $(\mathrm{C}+/ \mathrm{T}-/ \mathrm{L}-)$. In the negative patterning schedule, unreinforced compound presentations were mixed with reinforced component presentations (C-/T+/L+) (Pavlov, 1927, p. 144).

Contemporary theories of learning have treated compound stimuli in an atomistic fashion. That is to say, responding to a compound is thought to reflect the sum mation of the separate associate strengths of the components (e.g., Mackintosh, 1975; Pearce \& Hall, 1980; Rescorla \& Wagner, 1972). Empirically, the typical outcomes of compound-stimulus manipulations readily fit the description "additive summation." That is to say, reinforced training with a compound stimulus followed by tests with the individual components reveals that the compound stimulus commands a higher level of responding than either component (Kehoe \& Gormezano, 1980, pp. 360-

\footnotetext{
The junior authors mourn the death of the senior author, William $P$ Bellingham. This research was supported by grants from the Australian Research Grants Committee. The authors thank Peita Graham, John Hogan, Steven Provost, and Patricia Spicer for their assistance in collecting the data. Requests for reprints should be sent to E. J. Kehoe, School of Psychology, University of New South Wales, Kensington, N.S.W. 2033, Australia.
}

361). Similarly, reinforced training of the separate com. ponents followed by tests with the compound stimulus alsc yields a higher level of responding to the compound thar to the components (e.g., Weiss, 1972).

Despite the evidence for a summation process, there is also abundant evidence that a compound can act in $c$ Gestalt-like fashion as a functional unit. The evidence arises primarily from research with patterning schedules. which can produce explicit differential conditioning of $a$ compound and its components. Patterning was first reported by Pavlov (1927, p. 144) and, according to Razran $(1965,1971)$, has been obtained frequently in Sovie1 laboratories. In the English-language literature, positive and negative patterning have been obtained by Hul] (1940), with the human galvanic skin response (GSR), Woodbury (1943), with the dog's rewarded nose press, and Rescorla $(1972,1973)$, with the rat's rewarded barpress.

Patterning, particularly negative patterning, appears inimical to a simple summation rule. Responding to the reinforced compound in positive patterning might be construed as the summation of subthreshold associative strengths acquired to the separate components. However, there is no way that a lack of responding to the nonreinforced compound in negative patterning could represent the summation of the high levels of overt responding to the components (Woodbury, 1943). Additional evidence for the integration of compound stimuli has been 
obtained in conditional discriminations, which entail the differential reinforcement of symmetric combinations of stimuli (e.g., Blough, 1969, 1972; Heinemann \& Chase, 1970; Saavedra, 1975). For example, Saavedra conducted training of the rabbit's eyeblink response with four compounds composed of four components (A, B, C, and D). Compounds $\mathrm{AC}$ and $\mathrm{BD}$ were reinforced, and compounds $A D$ and $B C$ were not reinforced. Saavedra found that every subject displayed more CRs to the reinforced compounds than to the nonreinforced compounds. The discriminative responding could not have been obtained simply by responding differentially to the individual components, since each was included equally often in a reinforced compound and in a nonreinforced compound.

There have been a variety of attempts to reconcile the evidence of Gestalt-like processes found in patterning and conditional discriminations with the evidence for an atomistic summation process (see Kehoe \& Gormezano, 1980). The most prominent accounts have been the "neural afferent interaction" hypothesis (Hull, 1943, 1945) and the "unique stimulus" hypothesis (Rescorla, 1972, 1973; Whitlow \& Wagner, 1972). These hypotheses retain the atomistic summation principle, but they assume that the compound stimulus produces special stimuli that enter the summation process. These special stimuli presumably have the ability to acquire associative strengths that are independent of those acquired by the separate components.

Hull's hypothesis, when stripped of its neurophysiological garb, assumes that the central encodings of concurrent stimuli mutually modify each other. In other words, the encoding of a tone sounded alone $(T)$ is different from the encoding of the same tone in the context of the light $\left(\mathrm{T}^{\prime}\right)$. The same would be true for the light alone (L) versus the light in context of the tone $\left(\mathrm{L}^{\prime}\right)$. Thus, in successful positive patterning, the encodings of the stimuli in the compound $\left(\mathrm{T}^{\prime}, \mathrm{L}^{\prime}\right)$ would each acquire a positive associative strength and the encodings of the separate stimuli $(T, L)$ would each acquire low or negative associative strength. In negative patterning, a complementary pattern of associative strengths would emerge.

The unique-stimulus hypothesis was proposed to explain patterning within the framework of the otherwise atomistic Rescorla and Wagner (1972) model. The unique-stimulus hypothesis assumes that a two-element compound consists of the two separable elements and an additional stimulus that is unique to the compound (Rescorla, 1972, 1973; Whitlow \& Wagner, 1972). Accordingly, responding to a compound reflects the sum of the associative strength of the unique stimulus with the associative strengths of the components. In positive patterning, the unique stimulus would take on an excitatory value, since the compound stimulus is always reinforced. However, the associative strengths of the separable elements would stabilize at a zero value, because the decremental effects of the nonreinforced component presentations would eventually cancel the incremental effects of their presentation in reinforced compound trials. Conversely, a negative patterning procedure would yield high excitatory strengths for the components, whereas the associative strength of the unique stimulus, which is never reinforced, would become sufficiently inhibitory to yield a net associative strength of zero on compound trials (Kehoe \& Gormezano, 1980, p. 364).

Although the available hypotheses are able to reconcile Gestalt-like outcomes with summation outcomes, these hypotheses permit substantial variation in the strength of the Gestalt-like process. In Hull's contextual encoding hypothesis, the rate of patterning would be controlled by the degree of generalization between the alternate encodings of each stimulus, and in the uniquestimulus hypothesis, the rate of patterning would be controlled by relative salience of the unique stimulus. From a casual inspection of existing data, the Gestalt-like process would appear to be fairly strong, because both positive and negative patterning have emerged in roughly a symmetric fashion across sessions of training (Rescorla, 1972; Woodbury, 1943). The data have revealed that response acquisition to the reinforced stimulus proceeds rapidly to virtually $100 \%$ responses. The unreinforced stimuli also have shown initial acquisition to $100 \%$ responses, after which discriminative responding has appeared as a decline in responding to the unreinforced stimuli. Rescorla (1972) found that the decline in responding to the compound in negative patterning proceeded somewhat more slowly than the decline in responding to the components in positive patterning. However, the difference was not large. Woodbury (1943) used only one subject in each condition and, not surprisingly, failed to detect any difference between the rate of positive and negative patterning across training sessions.

The previous findings offer a slim base for reaching general conclusions about the nature and strength of Gestalt-like processes relative to summation processes. Furthermore, firm conclusions would be limited to instrumental appetitive procedures. With respect to classical aversive conditioning, Hull's (1940) report of GSR data does not provide sufficient detail to reach any conclusions. Given that there are relatively few studies of patterning, the present experiments were conducted to compare positive and negative patterning in two associative procedures: (1) appetitive conditioning of anticipatory magazine responses by the rat, and (2) aversive conditioning of the rabbit's nictitating membrane response.

\section{EXPERIMENT 1}

Experiment 1 compared positive and negative patterning on both a within- and between-subjects basis using appetitive conditioning of anticipatory magazine responses by rats.

\section{Method}

Subjects. The subjects were 16 male Wistar-hooded rats obtained from the Psychology Department's breeding colony at the Australian National University. The rats were $90-100$ days old at the start of 
the experiment. They were housed individually with free access to food. The animals were subjected to a $12 / 12 \mathrm{light} /$ dark cycle, with light on from $0600 \mathrm{~h}$.

Apparatus. Each subject was trained in one of four customdesigned chambers. Each chamber was enclosed in a wooden soundattenuating enclosure that was ventilated by a blower that provided a $75-\mathrm{dB}$ (SPL) masking noise. The chambers were $30.5 \times 20.0$ $\times 19.5 \mathrm{~cm}$ and were fitted with a water dipper activated by a rotary solenoid. The capacity of the cup mounted on the dipper arm was $.1 \mathrm{ml}$. The cup entered through the center of the floor of a magazine recess $(6.5 \times 6.5 \times 7.0 \mathrm{~cm})$ situated on the front wall. The floor of the chamber consisted of stainless steel bars, $1.0 \mathrm{~cm}$ in diameter and $1.3 \mathrm{~cm}$ apart, placed parallel to the front wall. A 24-V, 5 -W light bulb was mounted above a brushed plastic lens centered over the dipper cup and flush with the ceiling of the magazine recess. The light was pulsed at $5 \mathrm{~Hz}$ to provide a visual CS. When on, the light provided $550 \mathrm{~lx}$ at the magazine entrance. A 24-V houselight provided a low level of intertrial illumination (approximately $1.25 \mathrm{~lx}$ ). A miniature speaker was mounted in the back wall of the magazine recess and faced the entrance to the magazine. The speaker provided an auditory $\mathrm{CS}$, which was an $82-\mathrm{dB}, 1,000-\mathrm{Hz}$ tone that was pulsed at $5 \mathrm{~Hz}$ in phase with the light. The duration of both CSs was $8 \mathrm{sec}$. The sequence and timing of stimulus events were controlled by an Osborne computer equipped with appropriate interfaces.

Magazine entries were detected by photocells mounted on the side walls of the magazine recess $2.0 \mathrm{~cm}$ from the entrance itself and $.2 \mathrm{~cm}$ above the floor of the recess. In order to prevent the animals from lying with their snounts in the magazine recess, and thus breaking the photobeam continuously, a $1.5-\mathrm{cm}$-high stainless steel plate was positioned across the base of the magazine entrance. Magazine entries were recorded continuously by the computer.

Procedure. For 10 days prior to the beginning of the experiment, the animals were adapted to a 23.8 -h water-restriction schedule.
During the experiment, training sessions were conducted after 22.81 of water deprivation. Immediately after each session, water wa available for $12 \mathrm{~min}$ in the home cage. After the water-restriction schedule was established, the animals were randomly assigned th two groups $(n=8)$. One group, designated PNP, received, in suc cession, 25 days of training with a positive patterning schedule 25 days with a negative patterning schedule, and 25 days with : positive patterning schedule. The other group, designated NPN received the complementary order of training: negative patterning positive patterning, and negative patterning. Each day of training consisted of 50 compound trials, 25 tone trials, and 25 light trials In the positive patterning procedure, the compound trials were re inforced with a water presentation, and the separate tone and ligh trials were not reinforced. Conversely, in the negative patterning procedure, the compound trials were not reinforced and the separat tone and light trials were reinforced. On each trial, the programmer tone and/or light was presented for $8 \mathrm{sec}$. On reinforced trials, thi dipper was presented noncontingently during the last $3 \mathrm{sec}$ and wa: withdrawn simultaneously with the stimulus offset. The intertria interval (ITI) was $15 \mathrm{sec}$. However, if a magazine entry occurre during the ITI, the ITI was restarted. A conditioned response (CR was defined as any magazine entry during the initial $5 \mathrm{sec}$ of a CS For the purposes of analysis, multiple magazine entries during : CS were counted as a single CR.

\section{Results and Discussion}

Figures $1 \mathrm{a}$ and $1 \mathrm{~b}$ show the mean percentage of CR: to the compound, tone, and light across days for Group: PNP and NPN, respectively.

First schedule. The pattern of responding under bott initial schedules paralleled the results obtained by Wood. bury (1943) and Rescorla (1972). As illustrated in the lef

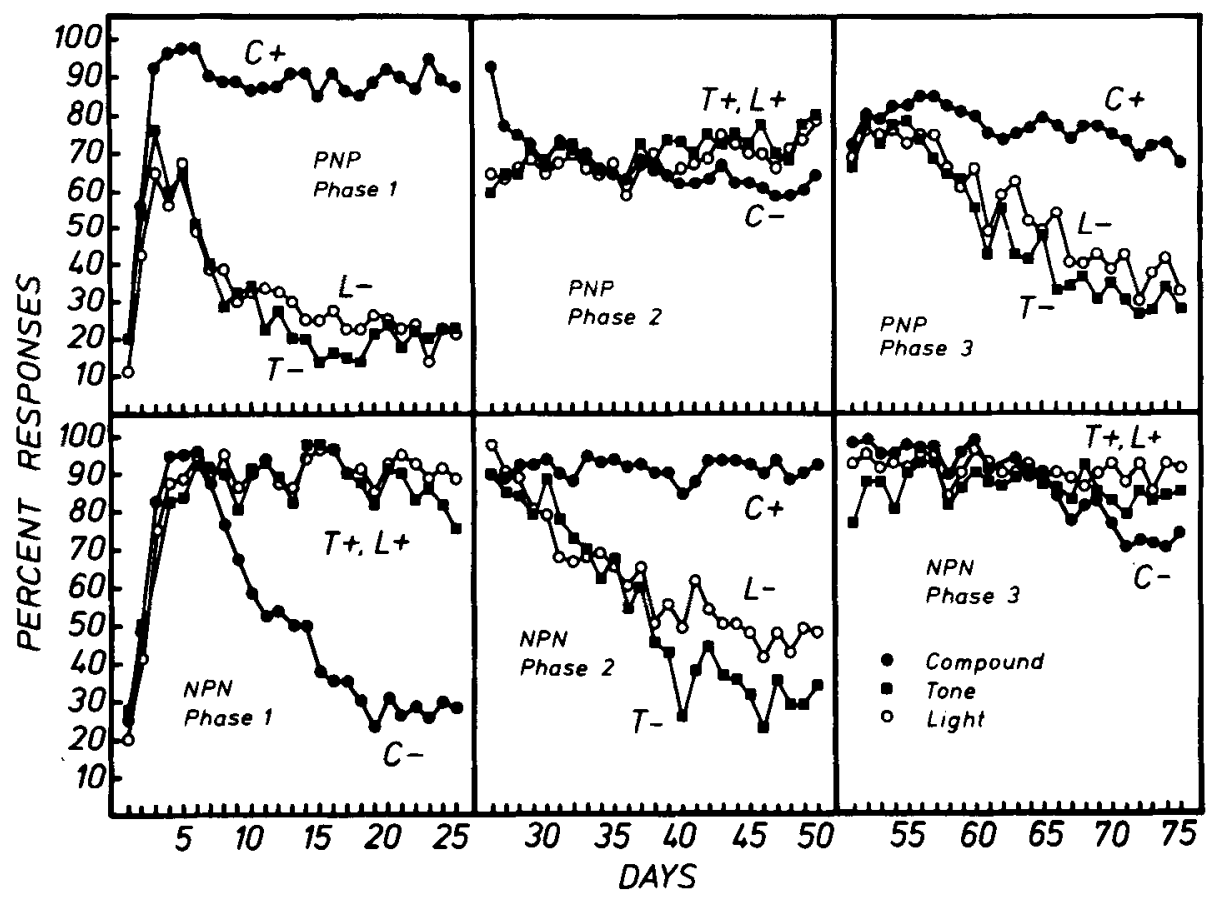

Figure 1. Mean percentage responses to the compound (C), tone (T), and light (L) as a function of days in Experiment 1, appetitive conditioning of magazine responses by the rat. The top row of panels shows the acquisition curves for Group PNP, which received training under, successively, positive, negative, and positive patterning schedules. The bottom row of panels shows the acquisition curves for Group NPN, which received training under, successively, negative, positive, and negative patterning schedules. 
half of each panel, both Group PNP and Group NPN initially showed rapid acquisition to both the compound and its components. Moreover, summation was evident, initially, in that the level of responding to the compound was higher than that to either the tone or light. However, discriminative responding between the compound and components became apparent after the first few sessions of training. In Group PNP, responding to the reinforced compound attained an asymptote of $90 \% \mathrm{CRs}$, while responding to the unreinforced components peaked at a mean of $70 \%$ CRs and then declined to an asymptote of $20 \%$ CRs by Day 14. Conversely, Group NPN showed a decline in responding to the unreinforced compound from a peak level of $96 \%$ CRs to an asymptote just under $30 \%$ CRs by Day 18. Responding to the reinforced components reached an asymptote of $90 \%$ CRs.

For purposes of statistical analysis, the data from Days $1-4,5-21$, and 22-25 were analyzed as separate sets of contrasts that included the factors of schedule (positive, negative), stimuli (compound, tone, and light), and days. The experimentwise Type I error rate was set at .05 and thus was set at .016 for each set of contrasts. Post hoc comparisons using the Scheffé technique [critical $F=$ $2 F(2,28)=12.96$ ] revealed the following: (1) Over Days $1-4$, responding was higher to the compound than to either component, regardless of the patterning schedule, but the statistical comparison failed to meet the stringent Scheffé criterion of significance $[F(2,28)=9.93]$. (2) By the end of training (Days 22-25), the levels of responding were significantly higher to the reinforced stimuli than to the unreinforced stimuli in both groups $[\mathrm{F}(2,28)=48.02]$. (3) Over Days 5-21, the overall magnitude of discrimination between the reinforced stimuli and the unreinforced stimuli failed to differ significantly between Groups PNP and NPN $[F(2,28)=1.16]$. However, the decline in responding to the unreinforced compound in the negative patterning schedule was slower than the decline in responding to the unreinforced components in the positive patterning schedule. Specifically, there was a significant interaction of stimuli (reinforced vs. nonreinforced) $X$ days (linear trend) $[F(2,28)=33.87]$.

Second schedule. Although the initial positive and negative patterning schedules produced symmetric outcomes, the switch to the alternate schedule produced distinctly asymmetric outcomes. In Group PNP, the switch to negative patterning produced a drop in responding to the compound and a very rapid rise in responding to the components. However, rather than crossing over, the levels of responding to the compound and the components converged at a level of $70 \%$ CRs. Responding remained at that level for approximately 12 days, after which a weak discrimination between the unreinforced compound and reinforced components appeared. Even at the end of 25 days of training, the level of responding to the compound was only 15 points below that of the components. In contrast to Group PNP's failure to successfully switch from positive to negative patterning, Group NPN showed a rapid crossover in responding to the compound and com- ponents after the switch from negative to positive patterning. Specifically, responding to the compound leapt from $22 \% \mathrm{CRs}$ at the end of the negative patterning schedule to a mean of $90 \%$ CRs within the first 50 reinforced compound trials of the positive patterning schedule. Responding to the unreinforced components declined somewhat more slowly but at a rate comparable to that seen in the initial positive patterning schedule of Group PNP. Responding to the unreinforced components stabilized at a mean of $45 \%$ CRs around the 15 th day after the switch to positive patterning. Statistical analysis of the data from the last day of the second schedule (Day 50) revealed that the difference in responding to the compound and components in Group PNP was significantly smaller than that in Group NPN $[F(2,28)=47.15]$.

Third schedule. The results of the reversal back to the original schedule confirmed the results of the earlier reversal. In Group PNP, the reversal back to positive patterning yielded steady declines in responding to the unreinforced components, while the level of responding to the reinforced compound hovered around $80 \%$ CRs. In Group NPN, the reversal from positive to negative patterning produced a rapid convergence in responding to both the compound and the components. Responding settled at a mean level of $90 \%$ CRs. Since Group NPN had initially shown very clear negative patterning, its failure to regain negative patterning after positive patterning provides a powerful confirmation that the failure to obtain negative patterning in Group PNP was no accident. In summary, positive patterning appears to interfere with negative patterning but not vice versa, which suggests that there is a fundamental asymmetry between the associations established by the two schedules.

\section{EXPERIMENT 2}

Experiment 2 examined positive and negative patterning in aversive conditioning of the rabbit's nictitating membrane response. Previously, negative patterning (Whitlow \& Wagner, 1972) and conditional discriminations (Saavedra, 1975) have been examined in conditioning of the rabbit's outer eyelid response. However, in the aversive conditioning literature, there is no reported demonstration of positive patterning, much less a comparison with negative patterning.

\section{Method}

Subjects. The subjects were 23 male and female albino rabbits obtained from the breeding unit of the University of New South Wales. The rabbits were 70-80 days old at the start of the experiment. They were housed individually with free access to food and water.

Apparatus. The apparatus and recording procedure for the nictitating membrane response were patterned after those of Gormezano (1966) and are detailed by Kehoe, Feyer, and Moses (1981). In brief, each subject was restrained in a Perspex box and trained individually in one of eight sound-attenuating, ventilated chambers. A speaker was mounted at a $45^{\circ}$ angle $8 \mathrm{~cm}$ anterior to and $16 \mathrm{~cm}$ above the subject's head. The speaker provided an auditory CS, which was a $1000-\mathrm{Hz}, 75-\mathrm{dB}(\mathrm{SPL})$ tone superimposed on an am- 
bient noise level of $72 \mathrm{~dB}$ provided by an exhaust fan. An 8-W frosted neon light tube was mounted $4 \mathrm{~cm}$ above the speaker. The light tube served as a houselight and was flashed at a rate of $20 \mathrm{~Hz}$ to provide a visual CS. The duration of both CSs was $800 \mathrm{msec}$. The US was a 50-msec, 3-mA, 50-Hz ac shock delivered via stainless steel Autoclip wound clips positioned $10 \mathrm{~mm}$ apart and $15 \mathrm{~mm}$ posterior to the dorsal canthus of the right eye. On reinforced trials, the CS-US interval (onset to onset) was $800 \mathrm{msec}$. The sequence and timing of stimulus events were controlled by an Apple II computer equipped with interfaces and software developed by Scandrett and Gormezano (1980).

The apparatus for transducing movements of the nictitating membrane differed in some respects from that described in previous reports. No straps were used to restrain the external eyelids. A chinrest (60 $\mathrm{mm}$ wide $\times 50 \mathrm{~mm}$ deep) was installed on the restrainer to ensure a uniform position of the head. The chinrest was mounted at a $30^{\circ}$ angle relative to horizontal. A muzzle-like headset, fitted about the snout of the rabbit, supported a transducer for monitoring movements of the nictitating membrane. A small tinned copper wire hook was attached to a silk loop sutured in the nictitating membrane of the rabbit's right eye. The other end of the hook contained a loop that fitted over another hook at the end of an L-shaped piano-wire lever. Inside the transducer, movement of the lever rotated a disk of polarized filter that was interposed between a lightemitting diode and a phototransistor covered by a fixed polarized filter. Thus, rotation of the disk produced changes in the intensity of the light reaching the transistor through the fixed filter. The sig- nal from the transistor was amplified and transmitted to an ana$\log$ /digital converter attached to the computer (Scandrett \& Gormezano, 1980).

Procedure. All rabbits received 1 day of preparation, 1 day of recovery, 1 day of adaptation, and 16 days of training. On the preparation day, hair surrounding each rabbit's right eye was removed and a small loop of silk (000 Dynex) was sutured into the nictitating membrane; the animals were returned to their home cages for 1 day of recovery. On the adaptation day, the animals were placed in the conditioning apparatus for $60 \mathrm{~min}$, but neither a CS nor a US was presented.

Following adaptation, the animals were assigned randomly to either a positive or negative patterning schedule. The experiment was run in three replications, but with a change in the proportion of reinforced to nonreinforced trials between the first and second replication. Accordingly, three groups received training with a positive patterning schedule and were designated $P 1(n=4), P 2(n=3)$, and $P 3(n=4)$. For Group P1, each day contained 30 reinforced compound trials $(\mathrm{C}+), 15$ unreinforced tone presentations $(\mathrm{T}-)$, and 15 unreinforced light presentations $(\mathrm{L}-)$. For Groups P2 and P3, each day contained $20 \mathrm{C}+, 20 \mathrm{~T}-$, and $20 \mathrm{~L}$ - trials. The other three groups received training with a negative patterning schedule and were designated N1 $(n=4), N 2(n=4)$, and N3 $(n=4)$. On each training day, Group $\mathrm{N} 1$ received $30 \mathrm{C}-, 15 \mathrm{~T}+$, and $15 \mathrm{~L}+$ trials, and Groups N2 and N3 received $20 \mathrm{C}-, 20 \mathrm{~T}+$, and $20 \mathrm{~L}+$ trials. In all schedules, no more than three trials of one type occurred consecutively. On reinforced trials, the onset of the US coincided with

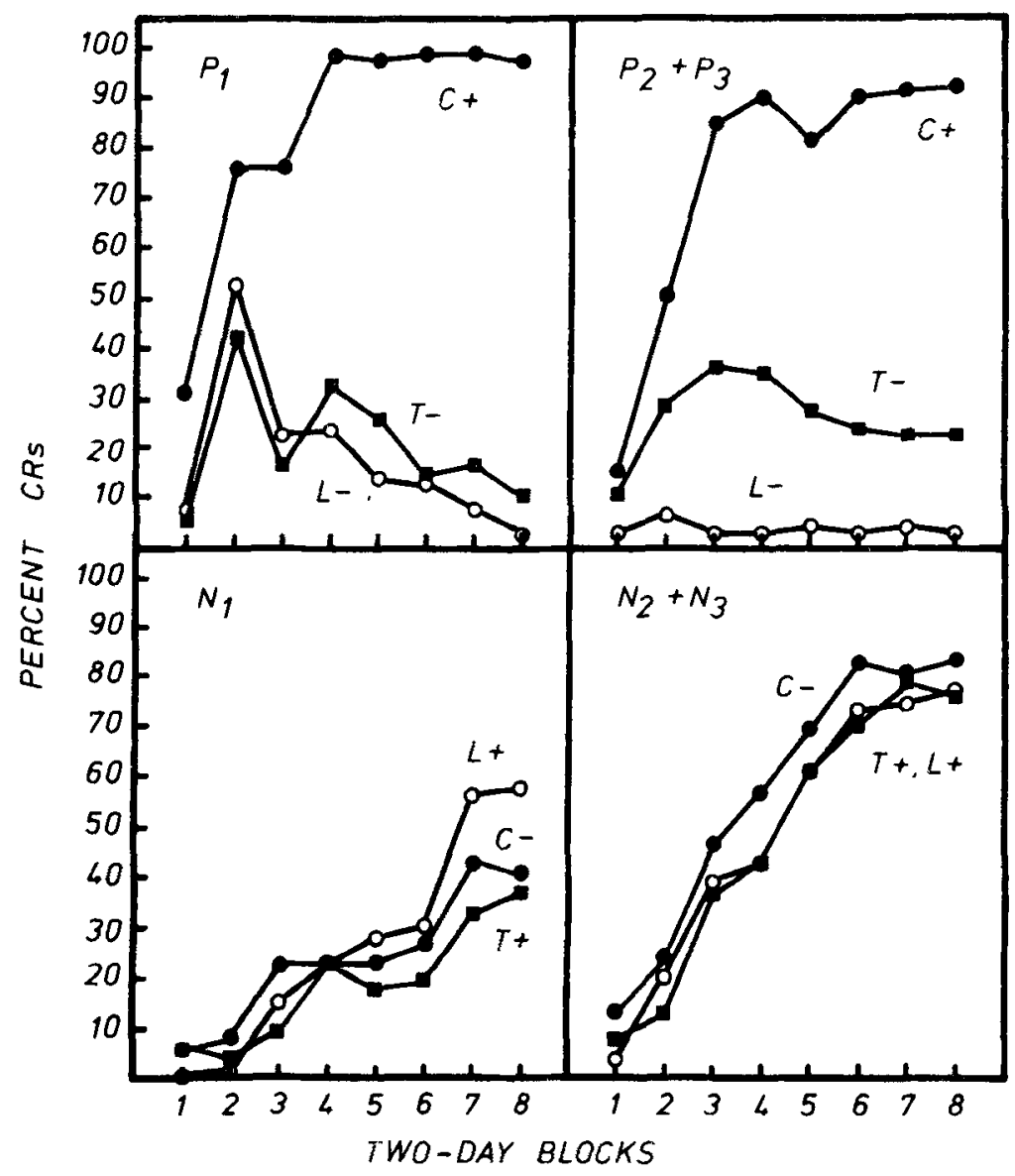

Figure 2. Mean percentage responses to the compound $(\mathrm{C})$, tone $(\mathrm{T})$, and light $(\mathrm{L})$ as a function of 2-day blocks in Experiment 2, aversive conditioning of the rabbit's NMR. The two top panels show the acquisition curves for Groups P1, P2, and P3, all of which received positive patterning schedules. The two bottom panels show the acquisition curves for Groups N1, N2, and N3, all of which received negative patterning schedules. 
the offset of the $800-\mathrm{msec} C S(s)$. The mean ITI was $60 \mathrm{sec}$ (range $40-80 \mathrm{sec}$ ). A conditioned response (CR) was defined as any extension of the nictitating membrane that exceeded $.5 \mathrm{~mm}$ following the onset of the CS but prior to its termination.

\section{Results and Discussion}

Figure 2 shows the mean percentage of CRs to the compound, tone, and light across days for all six groups. The results of Groups $\mathrm{P} 2$ and $\mathrm{P} 3$ have been averaged together, and the results of Groups N2 and N3 have been averaged together. In brief, positive patterning did appear, but negative patterning did not appear within the 16 days of training. However, as will be discussed below, an extension of training did eventually yield some negative patterning in Groups N2 and N3.

Examination of the performance by the positive patterning groups reveals that they showed rapid $\mathrm{CR}$ acquisition to the compound to a higher level than that of either the tone or light. The course of responding in Group P1 paralleled the results obtained in Experiment 1 and in Woodbury's (1943) and Rescorla's (1972) experiments. Specifically, Group P1 showed rapid acquisition to both the compound and the components. Summation was evident in that the level of responding to the compound was higher than that to either the tone or light. After Day 4, responding to the reinforced compound continued upward to an asymptote of $100 \% \mathrm{CRs}$, whereas responding to the unreinforced components peaked at a mean of $57 \%$ CRs and then declined to $0 \%$ CRs. Statistical analysis confirmed that there was a significant downward linear trend in responding to the components between Days 3-4 and Days $15-16[\mathrm{~F}(1,11)=5.22, \mathrm{p}<.05]$. Groups $\mathrm{P} 2$ and P3 also showed high levels of CR acquisition to the compound, but responding to the tone showed only a modest rise and an equally modest decline that stabilized just under 25\% CRs. Responding to the light in Groups P2 and P3 was negligible throughout training. At the termination of training, the level of responding to the compound in Groups P1 and P2 was significantly higher than responding to either component [smallest $F(1,11)=$ $17.41, \mathrm{p}<.05]$. Examination of the individual subjects in Groups P1, P2, and P3 revealed that 10 of the 11 subjects achieved virtually perfect patterning at the end of training. Among those subjects, the smallest difference between responding to the compound and either component was 72 points. The remaining subject, which was in Group P2, showed $100 \%$ CRs to the compound and the tone and $10 \%$ CRs to the light. Any apparent differences between Groups P1, P2, and Group P3 with respect to the compound, tone, or light failed to reach statistical significance.

Inspection of the performance of Groups $\mathrm{N} 1, \mathrm{~N} 2$, and $\mathrm{N} 3$ yielded no evidence of negative patterning. No subject consistently showed less responding to the compound than to the components. As can be seen in Figure 2, the subjects typically showed the same level of responding to the compound as they did to the components. The only notable difference was that Groups N2 and N3 showed significantly faster overall CR acquistion than did Group

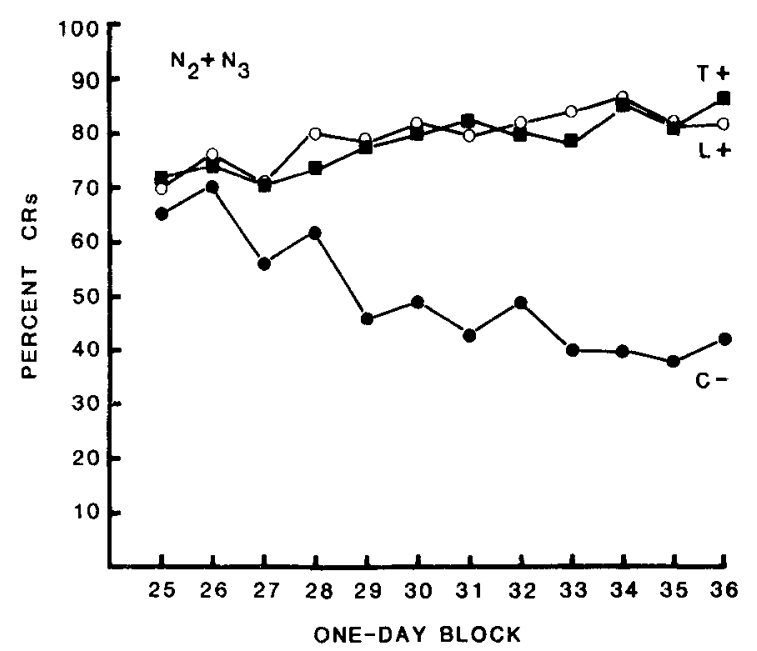

Figure 3. Mean percentage responses to the compound (C), tone (T), and light (L) by Groups N2 and N3 under a negative patterning schedule across Days 25-36 in Experiment 2.

$\mathrm{N} 1$, as was confirmed by a difference in linear trends across training in responding to the compound $[\mathrm{F}(1,11)$ $=7.20, \mathrm{p}<.05]$ and to the tone $[\mathrm{F}(1,11)=6.20$, $\mathrm{p}<.05]$, but not to the light $[\mathrm{F}(1,11)=2.04, \mathrm{p}=.18]$. Because Groups N2 and N3 achieved a high level of responding by Day 16, their training was continued in order to determine whether negative patterning would eventually emerge. It did. From Days 17 to 24 , responding to the compound and the components hovered around a mean of $80 \%$ CRs. From Day 25 onwards, the number of unreinforced compound trials was doubled from 20 to 40 . Figure 3 shows the mean percentage of CRs to the compound, tone, and light in Groups N2 and N3 for Days 25 through 36 . On Day 28 , the mean level of responding to the compound dropped below $70 \% \mathrm{CRs}$ and continued to decline on subsequent days, reaching a mean level of $42 \%$ CRs on Day 36. Throughout the same period, the level of responding to both the tone and the light steadily increased from a mean of $70 \%$ CRs to a terminal mean of $84 \%$ CRs. At the termination of training, the level of responding to the compound was significantly lower than the level of responding to the tone and light $[\mathrm{F}(1,7)=$ $17.42, p<.05$ ]. Among the eight subjects in Groups N2 and $\mathrm{N} 3$, six showed negative patterning; the remaining two subjects responded at equal levels to the compound and the components.

\section{GENERAL DISCUSSION}

The present experiments yielded the following major findings: (1) Appetitive conditioning of anticipatory magazine responses in the rat confirmed what has been found in appetitive conditioning of bar responses in the dog (Woodbury, 1943) and the rat (Rescorla, 1972). That is to say, initial training with positive and negative patterning schedules yielded roughly symmetric development of discriminative responding to a compound and its com- 
ponents. (2) However, the reversals of schedule in $\mathrm{Ex}^{-}$ periment 1 and the results of Experiment 2 revealed an asymmetry between positive and negative patterning. Specifically, in Experiment 1, positive patterning was relatively easy to obtain after a negative patterning schedule, but negative patterning was weak after a positive patterning schedule. In the aversive conditioning preparation of Experiment 2, positive patterning appeared rapidly, but even moderate negative patterning required extended training. In summary, positive patterning was very robust, whereas negative patterning appeared to be a delicate phenomenon.

In interpreting the present results, the need for parsimony requires that some consideration be given to the most straightforward summation principle. There are two reasons for ruling out a summation principle as sufficient. First, the development of negative patterning cannot be attributed to a summation of the associative strengths of the tone and light. It is true that the initial response acquisition to the unreinforced compound did agree with the expectations of a summation principle in that the level of responding to the compound equaled or exceeded the level of responding to the reinforced tone and reinforced light. By the same token, the ultimate decline in responding to the compound reveals a process that opposes summation of excitatory associative strengths. Second, some of the same logic can be applied to positive patterning. The mere fact that the level of responding to the compound is higher than that to the components is perfectly consistent with a summation principle. Where the summation principle runs into difficulty is in the changing relationship between the compound and the components, particularly when responding to the components declines while responding to the compound stays constant. In order to explain the relations between the compound and components at any given time in training, a defender of the summation principle could argue that there is a nonlinear mapping of associative strength onto overt responding. However, when the levels of responding to the components descend through virtually the entire response scale and responding to the compound remains largely unchanged, it becomes difficult to see how any fixed mapping function could reasonably account for the results of the positive patterning schedule.

\section{Computer Simulations of Patterning}

Although a summation principle is not sufficient, the present results only partly reveal the extra processes operative in compound stimuli. The contextual encoding hypothesis and unique-stimulus hypothesis can, of course, explain the occurrence of patterning, but it is not clear how well they can capture the more subtle features of the present findings. Accordingly, we explored these hypotheses through computer simulations (cf. Rescorla \& Wagner, 1972, p. 83). Furthermore, we explored a model that approximated a "pure" configuration hypothesis. In these simulations, we attempted to reproduce four features of the present findings. These were: (1) the initial rapid response acquisition to the compound and components in which summation was evident under both patterning schedules (cf. Rescorla, 1972; Woodbury, 1943); (2) the ultimate decline in responding to the unreinforced stimuli (cf. Rescorla, 1972; Woodbury, 1943); (3) the asymmetry in the reversal of the schedules, namely the virtual disappearance of negative patterning after positive patterning but not vice versa; and (4) the precipitous rise in responding to newly reinforced stimuli following a reversal of either schedule.

Unique-stimulus hypothesis. The unique-stimulus hypothesis is an amendment to the Rescorla-Wagner model. The model's basic equation for a change in the associative strength $(\mathrm{dVi})$ for a given stimulus i follows the formula:

$$
\mathrm{dVi}=\alpha_{\mathrm{i}} \beta(\lambda-\Sigma \mathrm{Vi}),
$$

where $\alpha$ is a direct function of the salience of stimulus $i$ $(0<\alpha<1), \beta$ is related to the intensity of the US ( 0 $<\beta<1$ ) (for unreinforced trials, we denoted $\beta$ as $\beta 0$ and assumed it to have a value greater than 0 ), $\lambda$ is the total associative strength that can be supported by the US on any given trial (we assumed that $\lambda=1.0$ on reinforced trials and that $\lambda=0.0$ on unreinforced trials), and $\Sigma \mathrm{Vi}$ is the net sum of the associative strengths of all concurrent stimuli. With this formula, we generated learning curves for the components and the compound by assuming that there were three relevant associative strengths: Vt for the separable tone component, Vl for the separable light component, and $\mathrm{Vu}$ for the hypothetical unique stimulus that arises whenever the compound of tone and light is presented. The $\alpha \mathrm{i}$ values for the tone ( $\alpha \mathrm{t})$ and light $(\alpha \mathrm{l})$ elements were fixed at .05 , while $\alpha \mathrm{i}$ for the unique stimulus $(\alpha \mathrm{u})$ was varied across values ranging from .001 to .05 . The value of $\beta$ was fixed at 1.00 for reinforced trials and was manipulated across the values ranging from 0.00 to 1.00 for unreinforced trials. The schedule of trials was identical to that in Experiment 1, in which half the trials were compound trials, a quarter were tone trials, and a quarter were light trials. Since none of the simulations specified the mapping of associative strength unto overt responding, we did not attempt to reproduce exact response levels but attempted only to approximate the ordinal relations in responding both within and between groups.

Figure 4 shows the learning curves for tone trials $(\mathrm{Vt})$, light trials $(\mathrm{Vl})$, and compound trials $(\mathrm{Vt}+\mathrm{Vl}+\mathrm{Vu})$ that were generated when both the salience of the unique stimulus and the rate parameter for unreinforced trials were low $(\alpha \mathrm{u}=.004, \beta 0=.33)$. The curves for the tone and light trials were combined because they were identical. The curves in Figure 4 show the values of the associative strengths at the end of the first 50 trials and at the end of every 100 trials thereafter. These curves represent the best approximation to the initial positive and negative patterning as seen in Experiment 1. Inspection of the lefthand panels of Figure 4 reveals that, in the first sched- 
trial, the apparent associative strength equaled $\mathrm{Vt}+\mathrm{gVt}^{\prime}$. On a compound trial, the apparent associative strength equaled $\mathrm{gVt}+\mathrm{gVl}+\mathrm{Vt}^{\prime}+\mathrm{Vl}^{\prime}$.

(4) The formula for a change in the associative strength of a stimulus representation followed a linear operator model like that used by Rescorla and Wagner (1972) but without the assumption that all concurrent stimuli competed for associative strength. For example, on a tone trial, the following formula applied:

$$
\mathrm{dVt}=\alpha \mathrm{t} \beta\left[\lambda-\left(\mathrm{Vt}+\mathrm{gVt}^{\prime}\right)\right]
$$

and on compound trials, the following formulas applied:

$$
\begin{aligned}
& \mathrm{dVt} \mathrm{t}^{\prime}=\alpha \mathrm{t} \beta\left[\lambda-\left(\mathrm{gVt}+\mathrm{Vt}^{\prime}\right)\right], \\
& \mathrm{dVl}^{\prime}=\alpha \mathrm{l} \beta\left[\lambda-\left(\mathrm{gVl}+\mathrm{Vl}^{\prime}\right)\right] .
\end{aligned}
$$

The contextual encoding simulation had one more stimulus than the unique-stimulus stimulation. Nevertheless, the simulation of the contextual encoding hypothesis had the same number of free parameters as the unique-stimulus simulation. The generalization parameter (g) essentially replaced the growth parameter of the unique stimulus $(\alpha u)$.

Figure 5 shows the learning curves for tone trials $\left(\mathrm{Vt}+\mathrm{gVt}^{\prime}\right)$, light trials $(\mathrm{Vl}+\mathrm{gVl})$, and the compound trials $\left(\mathrm{Vt}^{\prime}+\mathrm{Vl}^{\prime}+\mathrm{gVt}+\mathrm{gVl}\right)$. These curves were generated when the generalization factor was very high $(g=0.90)$ and the rate parameter for unreinforced trials was moderate $(\beta 0=.50)$. The curves for the tone and light trials were combined because they were identical. In brief, the learning curves generated by the contextual encoding simulation provided a slightly better approximation to the results than did the unique-stimulus simulation. Inspection of the left-hand panels reveals that both patterning schedules initially generated rapid acquisition to all stimuli and generated a summation outcome. After the initial rises, the net associative strength of the unreinforced stimuli in both positive and negative patterning showed pronounced declines parallel to those seen in Experiment 1 . The best approximation to the slow emergence of negative patterning in Experiment 2 was obtained when both the generalization parameter and the rate parameter

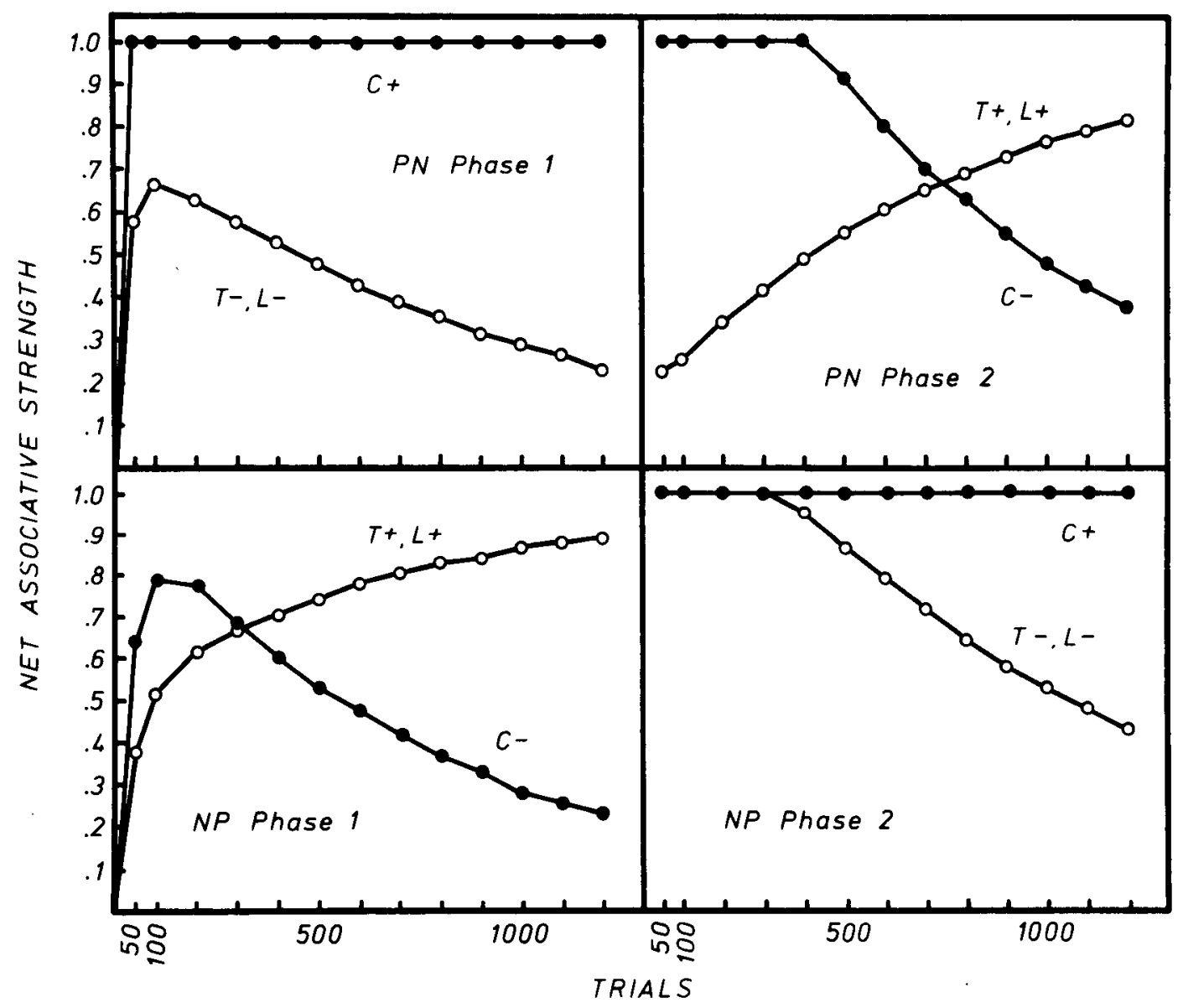

Figure 5. Simulation of a contextual encoding hypothesis. Net associative strength of the compound (C), tone (T), and light $(\mathrm{L})$ as a function of trials. The top row of paneis shows changes in associative strength under a positive patterning schedule and under a subsequent negative patterning schedule. The bottom row of panels shows changes in associative strength under a negative patterning schedule followed by a positive patterning schedule. 


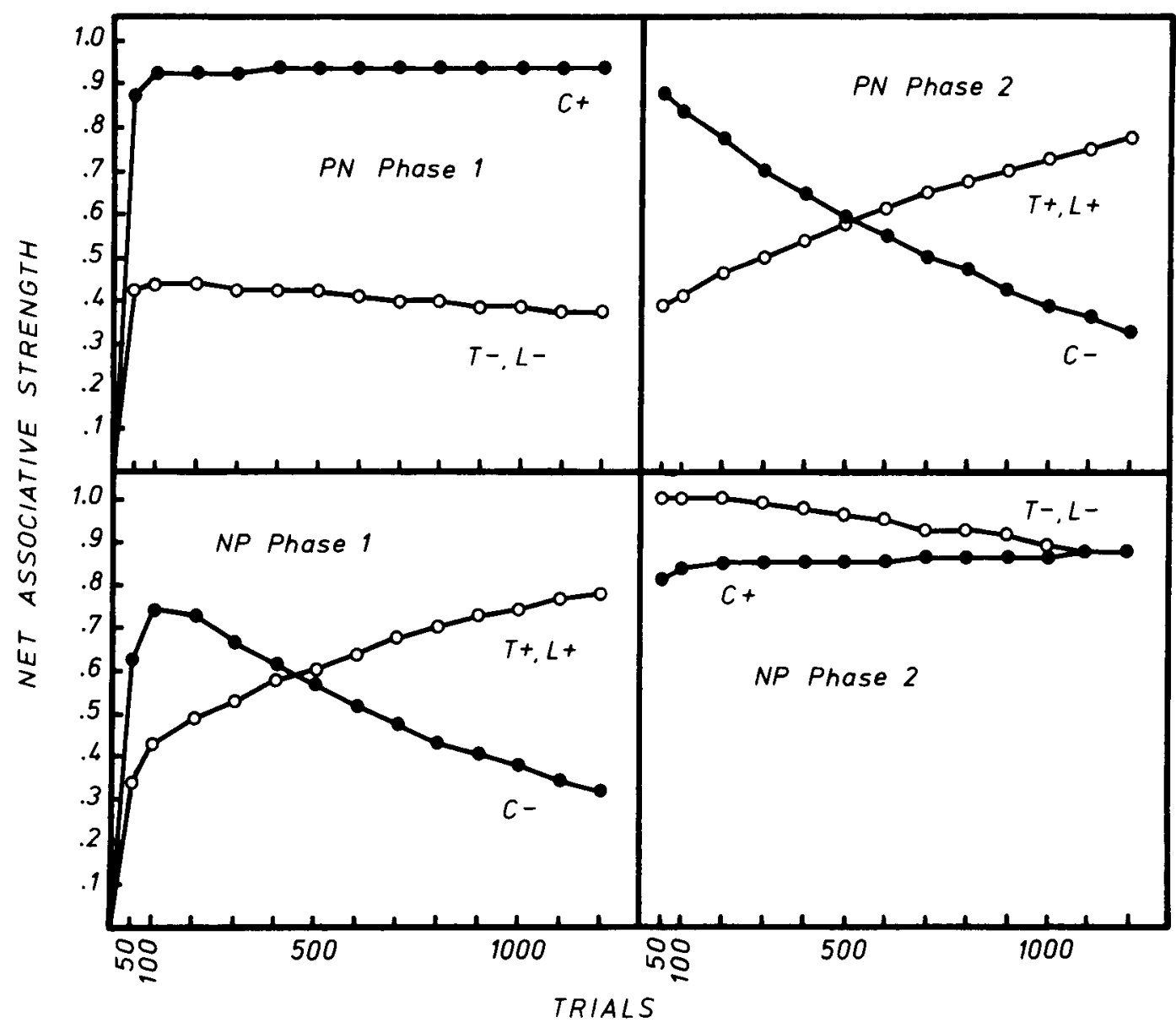

Figure 4. Simulation of the unique-stimulus hypothesis. Net associative strength of the compound (C), tone (T), and light (L) as a function of trials. The top row of panels shows changes in associative strength under a positive patterning schedule and under a subsequent negative patterning schedule. The bottom row of panels shows changes in associative strength under a negative patterning schedule followed by a positive patterning schedule.

ule, both the positive and negative schedules initially yielded acquisition to all stimuli as well as summation. Thereafter, appropriate patterning appeared through a decline in the net associative strength of the unreinforced stimuli. However, in the case of positive patterning, the decline was relatively slight. Increasing either $\alpha \mathrm{u}$ or $\beta 0$ had little effect on the outcome of positive patterning. With respect to negative patterning, increases in the salience of the unique stimulus $(\alpha u)$ largely eliminated the initial summation and hastened the appearance of negative patterning. Increases in the rate parameter for unreinforced trials $(\beta 0)$ dramatically retarded the rate of overall acquisition and the appearance of negative patterning, thus duplicating the slow appearance of negative patterning in Experiment 2. Inspection of the right-hand panels of Figure 4 reveals that a reversal of the schedules generated results opposite to those actually obtained. That is to say, within the unique-stimulus simulation, positive patterning proceeded slowly relative to negative patterning. Further searches of possible parameters revealed that the only parameter values that approximated the reversal findings (but not the initial findings) were ones in which (1) the unique stimulus had low salience $(\alpha \mathrm{u}=.005)$ and (2) the rate parameter for unreinforced trials $(\beta 0=1.33)$ exceeded that of reinforced trials $(\beta 1=1.00)$.

Contextual encoding hypothesis. The contextual encoding hypothesis was originally part of Hull's larger set of axioms concerning excitatory and inhibitory conditioning. In order to simulate the contextual encoding hypothesis, the following assumptions were made:

(1) Each physical stimulus, namely the tone and light, generated two alternate representations, one for the stimulus in the context of the compound $\left(\mathrm{T}^{\prime}, \mathrm{L}^{\prime}\right)$ and one for the stimulus outside the context of the compound $(T, L)$.

(2) Each stimulus representation could take on an independent associative strength. These associative strengths were designated $\mathrm{Vt}^{\prime}, \mathrm{Vl}^{\prime}, \mathrm{Vt}$, and $\mathrm{Vl}$, respectively.

(3) The associative strengths of the alternate representations were related by a generalization parameter, $\mathrm{g}(0<\mathrm{g}<1)$. Thus, on a given trial, the apparent associative strength of a physical stimulus was determined by the net sum of the associative strength of the appropriate representation and the generalized associative strength of the alternate representation. For example, on a tone 
for unreinforced trials were extremely high $(\mathrm{g}=.99$, $\beta 0=1.00$ ). Inspection of the right-hand panels of Figure 5 reveals that the contextual encoding simulation accurately reproduced the reversal from negative to positive patterning. In agreement with the results of Experiment 1 , the associative strength of the newly reinforced compound stimulus showed an abrupt rise to the asymptote, whereas the newly unreinforced component stimuli showed a slow decline. However, the contextual encoding simulation yielded a less satisfactory result for the reversal from positive to negative patterning. In the generated curves, the newly unreinforced compound showed a slow decline and the newly reinforced components showed a slow rise, the curves crossing over about halfway through the simulation run. In the results of Experiment 1, responding to all stimuli rapidly converged at a mean level of $75 \%$ CRs and showed only a slight suggestion of negative patterning toward the end of the reversal training. Further searches of possible parameters indicated that the reversal from positive to negative patterning was better approximated when the generalization parameter was increased $(\mathrm{g}=.99)$ and the parameter for unreinforced trials was reduced $(\beta 0=.15)$. Under the altered parameters, the net associative strength of the newly reinforced components rose rapidly to a stable value of approximately .75 , but the net associative strength of the unreinforced compound showed only slight declines and remained at a value greater than 1.00 .

Configural hypothesis. Two key features characterize configural hypotheses. First, all configural hypotheses assume that the subject encodes a compound as a single effective stimulus distinct from its components (Gray \& Lethbridge, 1976; Heinemann \& Chase, 1970; Kehoe \& Gormezano, 1980, pp. 354-356; Razran, 1965, 1971; Young \& Pearce, 1984; Zuckerman, 1973). Second, except for Razran, who contends that the configural unit becomes completely distinct from its components, advocates of a configural hypothesis assume that the subject generalizes to some degree from the configural unit to each component (cf. Baker, 1972; Gillette \& Bellingham, 1982; Heinemann \& Chase, 1970; Kehoe, 1982; Young \& Pearce, 1984; Zuckerman, 1973). Recently, Young and Pearce have indicated that a configural hypothesis could be incorporated into the mechanics of contemporary associative learning theories (see, e.g., Pearce \& Hall, 1980; Rescorla \& Wagner, 1972). In order to simulate a configural hypothesis in a manner consistent with our two other simulations, the following assumptions were used:

(1) The tone, light, and compound each generated a separate representation.

(2) Each stimulus representation could take on an independent associative strength. These associative strengths were designated $\mathrm{Vt}, \mathrm{Vl}$, and $\mathrm{Vc}$, respectively.

(3) Generalization from the compound to the components and vice versa was related by a generalization parameter, $\mathrm{g}(0<\mathrm{g}<1)$. Thus, on a given trial, the observed associative strength of a physical stimulus was determined by the net sum of its own associative strength and any generalized associative strength. For example, on a tone trial, the observed associative strength equaled $\mathrm{Vt}+\mathrm{gVc}$. On a compound trial, the observed associated strength equaled $\mathrm{gVt}+\mathrm{gVl}+\mathrm{Vc}$.

(4) The formula for change in the associative strength of a stimulus representation followed a linear operator model like that of Rescorla and Wagner (1972). In brief, generalized associative strengths determined the animal's evaluation of the difference between current associative strength and the asymptotic value supported by the US. However, only the representation of the current event could gain or lose associative strength. For example, on a tone trial, the following formula applied:

$$
\mathrm{dVt}=\alpha \mathrm{t} \beta[\lambda-(\mathrm{Vt}+\mathrm{gVc})],
$$

and on compound trials, the following formula applied:

$$
\mathrm{dVc}=\alpha \mathrm{c} \beta[\lambda-(\mathrm{gVt}+\mathrm{gVl}+\mathrm{Vc})],
$$

Figure 6 shows the learning curves for tone trials $(\mathrm{Vt}+\mathrm{gVc})$, light trials $(\mathrm{Vl}+\mathrm{gVc})$, and compound trials $(\mathrm{gVt}+\mathrm{gVl}+\mathrm{Vc})$. These curves were generated when both the generalization factor and the rate parameter for unreinforced trials were moderate $(\mathrm{g}=.50 ; \beta 0=.33)$. The curves for the tone and light trials were combined because they were identical. Like the other two simulations, the configural simulation yielded positive patterning in Phase 1 without difficulty. In the case of initial negative patterning, the configural simulation may have produced a slightly better approximation to our findings than did the other two hypotheses. In the initial negative patterning schedule of both experiments, the summation effect was at best small prior to the ultimate decline in responding to the compound. The other two simulations yielded rather pronounced summation effects, but the curves from the configural simulation initially showed no differentiation between the compound and the components. In dealing with the transfer from negative patterning to positive patterning, the configural simulation did better than the unique-stimulus simulation but worse than the contextual encoding simulation. That is to say, the configural simulation did predict accurately that positive patterning would emerge relatively rapidly following a reversal from negative patterning. However, the configural simulation failed to capture the abrupt rise in responding to the compound following the switch to reinforced compound presentations. With respect to the loss of negative patterning following positive patterning, the configural simulation performed much the same as the other two simulations. That is to say, the simulation produced a slow crossover in responding to components and the compound.

Evaluation. In viewing the three simulations and their results, we were just as impressed by their similarities as we were by their differences in what they reveal about the nature of patterning. In terms of their structural features, each of the three models represents a compromise among assumptions regarding summation of associative 


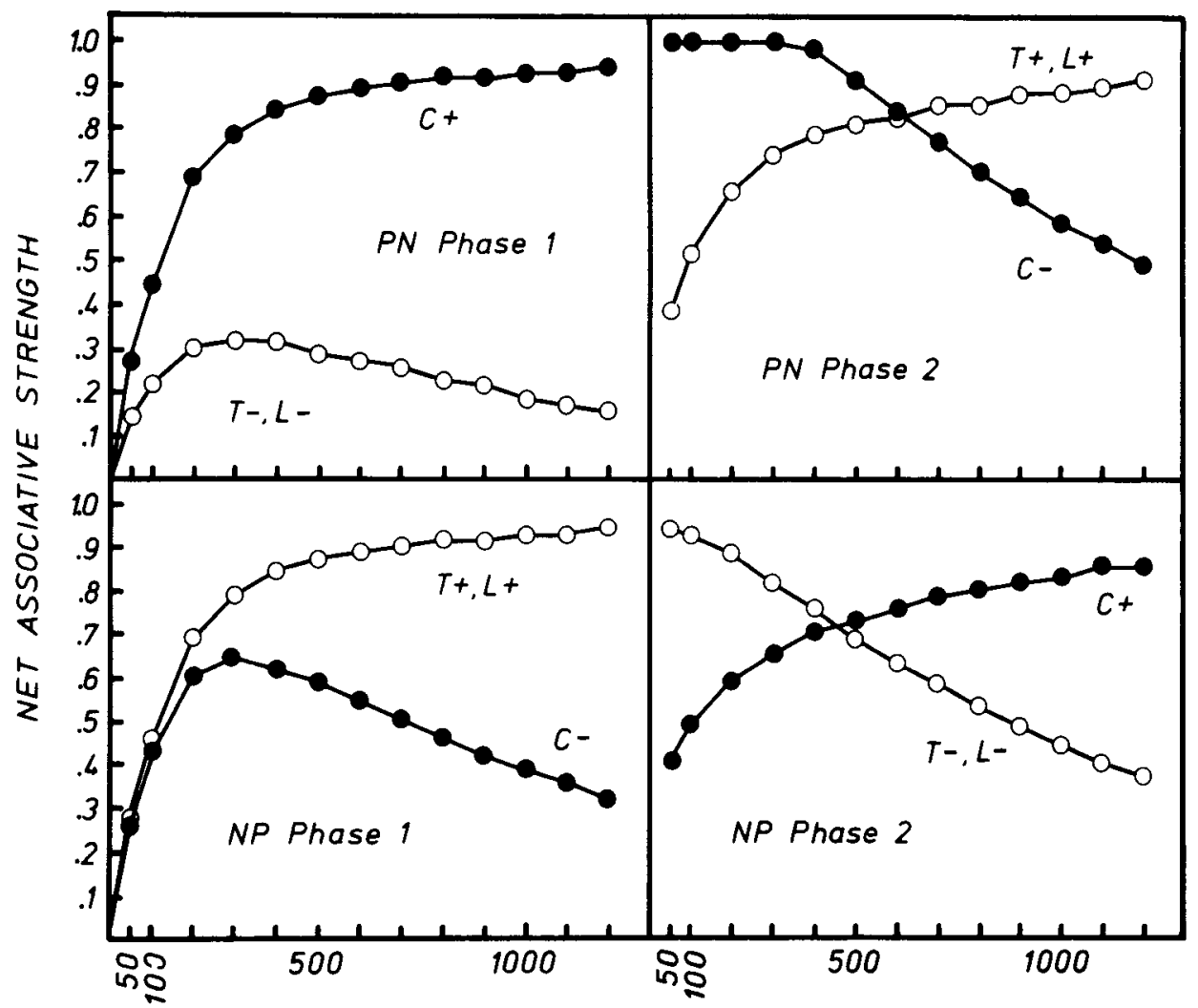

TRIALS

Figure 6. Simulation of a configural hypothesis. Net associative strength of the compound (C), tone (T), and light $(L)$ as a function of trials. The top row of panels shows changes in associative strength under a positive patterning schedule and under a subsequent negative patterning schedule. The bottom row of panels shows changes in associative strength under a negative patterning schedule followed by a positive patterning schedule.

strengths, perceptual interaction among the components, and generalization among the compound and component trials.

Summation. All three models assume that summation of associative strengths determines the acquisition and expression of associative strength for current stimulus representations. The unique-stimulus model has the most atomistic content, assuming that only the associative strengths of the current events summate. In contrast, the contextual encoding model and configural model assume that generalized associative strengths enter the summation process as well as those of current events.

Perceptual interaction. All three models assume that there is a perceptual interaction between the components on compound trials. Again, the unique-stimulus model is the most atomistic. Although it assumes that there is a distinctive representation of the compound, the model retains independent and unmodified representations of the components. In contrast, the formal differences between the contextual encoding model and the configural model are much smaller than their qualitative descriptions might lead one to believe. Both models assume that there is a complete alteration in the stimulus representations on compound trials. The contextual encoding model depicts these alterations as changes in the representations of the components; the configural model represents the alterations in terms of a single fused representation. Since the contextual encoding model assumes that altered representations of the components always occur together, it is not entirely clear whether either representation scheme has an advantage over the other.

Generalization. The contextual encoding model and configural model both assume that there is mutual generalization of associative strengths between the compound and component trials. These generalized associative strengths determine the net associative strength for purposes of performance and changes in associative strength. In contrast, the unique-stimulus model makes the simpler assumption that generalization does not play a part, although there is carryover between the compound and component trials via the associative strengths of the component representations.

None of the models yielded an entirely convincing approximation to the data, and each of them is subject to a variety of refinements. However, it did appear that the unique-stimulus simulation was the widest of the mark, particularly in its inaccurate predictions regarding the reversal results. There is less to distinguish between the 
contextual encoding model and configural model. As noted above, their formal structures closely resemble each other, as do their results. On the one hand, the contextual encoding model was more accurate in depicting the reversal from negative to positive patterning, particularly the abrupt rise in responding to the compound. On the other hand, the configural model somewhat more closely approximated the curves seen in initial negative patterning.

\section{Conclusion}

On the basis of our empirical findings and our simulations, the nervous system appears to process concurrent stimuli in three stages. First, there is an encoding stage. Even for compounds consisting of stimuli from separate sensory modalities, there appears to be a perceptual interaction between them. Patterning, particularly negative patterning, could not proceed without such an interaction. Historically, the controversy between configural and atomistic approaches has focused on the degree of fusion between the components of a compound (Baker, 1968; Bellingham \& Gillette, 1981; Kehoe \& Gormezano, 1980; Razran, 1971). Our attempts to formalize these approaches and simulate our findings revealed two features about the perceptual interaction. First, it need not be very strong. In particular, the simulation of the unique-stimulus hypothesis indicated that the salience of the unique stimulus was an order of magnitude smaller than the salience of the isolable stimulus elements. Similarly, the simulation of the contextual encoding hypothesis indicated that there might be massive generalization $(g=.90)$ between the alternate representations of the individual stimuli. Even the configural simulation indicated that there might be appreciable generalization between the compound representation and the component representations $(g=.50)$. Second, the present simulations suggested that the nature of the supposed perceptual interaction could not be readily divorced from assumptions about summation and generalization that affect the expression of associative strength and changes in associative strength on each trial. Consequently, the second stage of processing involves the establishment of an independent association for each of the functional stimuli, and the third stage of processing involves the behavioral output. In both cases, the algebraic sum of current and/or generalized associative strengths triggered by the current stimulus representations was of crucial importance. The summation of associative strengths appears to be an inescapable feature of any formal model. Even the configural model relies heavily on the summation of generalized associative strengths. So far as we know, summation has been the preferred way to systematically combine the results of generalization among disparate events. Other formal attempts to describe multidimensional generalization gradients have inevitably entailed a metric of perceptual distance, to which our $\mathrm{g}$ factor corresponds, and a combination rule for combining the net response strength of generalization along several sensory dimensions (Kehoe \& Gormezano, 1980, pp. 370-373). Even nonmetric multidimensional scaling uses a summation rule (e.g., Shepard, 1974, p. 414). It is less clear whether generalization among stimulus representations is essential to an accurate model of configural learning. Certainly, there has to be some commonality between a compound and its components. Otherwise, configural learning would be trivially easy. However, generalization expressed as a metric of perceptual distance is not the only solution. In the present simulations, the unique-stimulus model can be construed as a "common elements" model, in which the representation of the separable element that occurs on compound and component trials is effectively a common element (Gillette, 1980). Whether a more sophisticated commonelements approach would be distinguishable from a generalization approach remains to be ascertained.

\section{REFERENCES}

BaKer, T. W. (1968). Properties of compound conditioned stimuli and their components. Psychological Bulletin, 70, 611-625.

BAKER, T. W. (1972). Component dynamics within compound stimuli. In R. F. Thompson \& J. F. Voss (Eds.), Topics in learning and performance. New York: Academic Press.

Bellingham, W. P., \& Gillette, K. (1981). Spontaneous configuring to a tone-light compound using appetitive training. Learning and Motivation, 12, 420-434.

Blough, D. S. (1969). Attention shifts in a maintained discrimination. Science, 166, 125-126.

BLougH, D. S. (1972). Recognition by the pigeon of stimuli varying in two dimensions. Journal of the Experimental Analysis of Behavior, 18, 345-367.

GILLETTE, K. A. (1980). Responses by rats to complex gustatory stimuli: A study of configurational learning. Unpublished doctoral dissertation, Australian National University, Canberra, ACT.

Gillette, K., \& Bellingham, W. P. (1982). Loss of within-compound flavour associations: Configural preconditioning. Experimental Animal Behaviour, 1, 1-17.

Gormezano, I. (1966). Classical conditioning. In J. B. Sidowski (Ed.), Experimental methods and instrumentation in psychology. New York: McGraw-Hill.

Gray, T., \& Lethbridge, D. A. (1976). Configural conditioning in the CER: Loss of element strength after repeated reinforced compound CS trials. Learning and Motivation, 7, 532-539.

Heinemann, E. G., \& Chase, S. (1970). Conditioned stimulus control. Journal of Experimental Psychology, 84, 187-197.

HuLL, C. L. (1940). Exploration in the patterning of stimuli conditioned to the GSR. Journal of Experimental Psychology, 27, 95-110.

Hull, C. L. (1943). Principles of behavior. New York: AppletonCentury-Crofts.

Hull, C. L. (1945). The discrimination of stimulus configurations and the hypothesis of neural afferent interaction. Psychological Review, 52, 133-139.

KeHOE, E. J. (1982). Overshadowing and summation in compound stimulus conditioning of the rabbit's nictitating membrane response. Journal of Experimental Psychology: Animal Behavior Processes, 8 , 313-328.

Kehoe, E. J., Feyer, A., \& Moses, J. L. (1981). Second-order conditioning of the rabbit's nictitating membrane response as a function of the CS2-CS1 and CS1-US intervals. Animal Learning \& Behavior, 9, 304-315.

Kehoe, E. J., \& Gormezano, I. (1980). Configuration and combination laws in conditioning with compound stimuli. Psychological Bulletin, 87, 351-378.

MACKINTOSH, N. J. (1975). A theory of attention: Variation in the associability of stimuli with reinforcement. Psychological Review, 82 , 276-298. 
Pavlov, I. P. (1927). Conditioned reflexes (G. V. Anrep, Trans.). London: Oxford University Press.

Pearce, J. M., \& Hall, G. (1980). A model for Pavlovian conditioning: Variations in the effectiveness of conditioned but not of unconditioned stimuli. Psychological Review, 87, 532-552.

RAZRAN, G. (1965). Empirical codifications and specific theoretical implications of compound-stimulus conditioning: Perception. In W. F. Prokasy (Ed.), Classical conditioning (pp. 226-248). New York: Appleton-Century-Crofts.

RaZran, G. (1971). Mind in evolution. New York: Appleton-CenturyCrofts.

Rescorla, R. A. (1972). "Configural" conditioning in discrete-trial bar pressing. Journal of Comparative and Physiological Psychology, 79, 307-317.

REsCorla, R. A. (1973). Evidence for the "unique stimulus" account of configural conditioning. Journal of Comparative and Physiological Psychology, 85, 331-338.

Rescorla, R. A., \& Wagner, A. R. (1972). A theory of Pavlovian conditioning: Variations in the effectiveness of reinforcement and nonreinforcement. In A. H. Black \& W. F. Prokasy (Eds.), Classical conditioning II. New York: Appleton-Century-Crofts.

SAAVEDRA, M. A. (1975). Pavlovian compound conditioning in the rabbit. Learning and Motivation, 6, 314-326.
SCANDRETt, J. \& Gormezano, I. (1980). Microprocessor control and A-D data acquisition in classical conditioning. Behavior Research Methods \& Instrumentation, 12, 120-125.

SHEPARD, R. N. (1974). Representation of structure in similarity data: Problems and prospects. Psychometrika, 39, 373-421.

WeIss, S. J. (1972). Stimulus compounding in free-operant and classical conditioning. Psychological Bulletin, 78, 189-208.

Whitlow, J. W., \& WagNeR, A. R. (1972). Negative patterning in classical conditioning: Summation of response tendencies to isolable and configural components. Psychonomic Science, 27, 299-301.

Woodbury, C. B. (1943). The learning of stimulus patterns in dog. Journal of Comparative Psychology, 35, 29-40.

Young, D. B., \& PeARCE, J. M. (1984). The influence of generalization decrement on the outcome of a feature-positive discrimination. Quarterly Journal of Experimental Psychology, 36B, 331-352.

ZuCKerman, D. C. (1973). Steady state responding based upon simple and compound stimuli. Journal of the Experimental Analysis of Behavior, 20, 209-218.

(Manuscript received November 20, 1984; revision accepted for publication April 29, 1985.) 